\title{
Chiral Iridium(III) Complexes in Light-Emitting Electrochemical Cells: Exploring the Impact of Stereochemistry on the Photophysical Properties and Device Performances
}

\author{
Diego Rota Martir, ${ }^{\dagger}$ Cristina Momblona, ${ }^{\ddagger}$ Antonio Pertegás, ${ }^{\ddagger}$ David B. Cordes, ${ }^{\dagger}$ Alexandra M. Z. Slawin, ${ }^{\dagger}$
} Henk J. Bolink, ${ }^{\ddagger}$ and Eli Zysman-Colman* ${ }^{\dagger}+$ (1)

${ }^{\dagger}$ Organic Semiconductor Centre, EaStCHEM School of Chemistry, University of St Andrews, St Andrews, Fife KY16 9ST, United Kingdom

${ }^{\ddagger}$ Instituto de Ciencia Molecular, Universidad de Valencia, c/Catedrático J. Beltrán, 2, Paterna 46980, Spain

Supporting Information

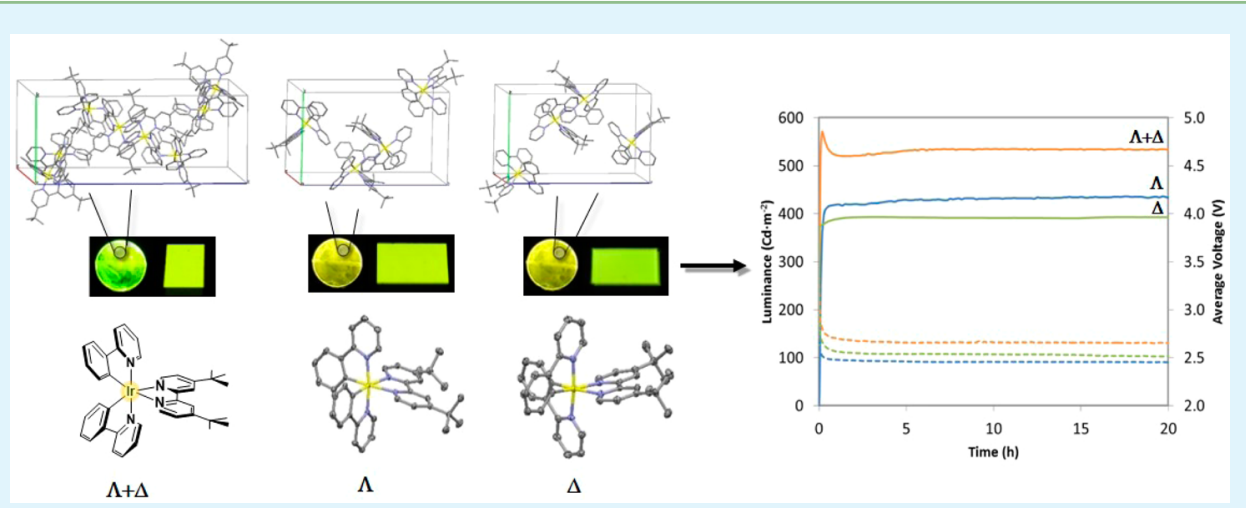

ABSTRACT: Despite hundreds of cationic bis-cyclometalated iridium(III) complexes having been explored as emitters for lightemitting electrochemical cells (LEECs), uniformly their composition has been in the form of a racemic mixture of $\Lambda$ and $\Delta$ enantiomers. The investigation of LEECs using enantiopure iridium(III) emitters, however, remains unprecedented. Herein, we report the preparation, the crystal structures, and the optoelectronic properties of two families of cyclometalated iridium(III) complexes of the form of $\left[\left(\mathrm{C}^{\wedge} \mathrm{N}\right)_{2} \operatorname{Ir}(\mathrm{dtBubpy})\right] \mathrm{PF}_{6}$ (where dtBubpy is 4,4'-di-tert-butyl-2,2'-bipyridine) in both their racemic and enantiopure configurations. LEEC devices using $\Lambda$ and $\Delta$ enantiomers as well as the racemic mixture of both families have been prepared, and the device performances were tested. Importantly, different solid-state photophysical properties exist between enantiopure and racemic emitters, which are also reflected in the device performances.

KEYWORDS: enantiopure complexes, cationic iridium(III) complexes, solid-state packing, photophysical properties, light-emitting electrochemical cells

\section{INTRODUCTION}

Iridium(III) ionic transition-metal complexes (iTMCs) are by far the most widely investigated class of emitter employed in light-emitting electrochemical cells (LEECs). ${ }^{1-4}$ In this type of electroluminescent device, iTMCs along with their associated counterions play several key roles, including the following: facilitating charge injection from the electrodes; charge transport through the device; and, after electron and hole recombination, emission of light. ${ }^{1}$ As a function of this simple single-layer architecture, LEECs have been targeted as a promising and potentially lower-cost alternative solid-state lighting technology to organic light-emitting diodes (OLEDs). ${ }^{5}$

Ionic cyclometalated iridium(III) complexes are the most popular emitters used in LEECs as they generally possess relatively short-lived triplet excited states $\left(\tau_{\mathrm{e}}\right)$, high photoluminescence quantum yields $\left(\Phi_{\mathrm{PL}}\right)$, and a huge variety of chemically stable complexes covering emissions over the entire visible spectrum, all pivotal properties for emitters in EL devices. $^{6-9}$ Octahedral iridium complexes bearing at least two bidentate ligands exhibit intrinsic metal-centered stereochemistry. ${ }^{10-12}$ During the prototypical synthesis of cationic bis-cyclometalated iridium(III) complexes of the form [Ir$\left.\left(\mathrm{C}^{\wedge} \mathrm{N}\right)_{2}\left(\mathrm{~N}^{\wedge} \mathrm{N}\right)\right]^{+}$, the two stereoisomers $(\Lambda, \Delta)$ are formed as a racemic mixture. Generally, in order to obtain enantiopure metal complexes, chiral resolution of the racemic mixtures is required to isolate the pure $\Lambda$ and $\Delta$ enantiomers. ${ }^{11,13-19}$ This can be achieved by purification by liquid chromatography using either a chiral stationary phase $e^{13,20-22}$ or a chiral anion in the eluent (cation-exchange chromatography). ${ }^{23,24}$ More recently, the concept of auxiliary-mediated asymmetric synthesis by

Received: November 3, 2016

Accepted: November 16, 2016

Published: November 16, 2016 
Chart 1. Chemical Structures of the Two Families of Complexes: (a) 1a, 1b, 1c and (b) 2a, 2b, 2c

a)

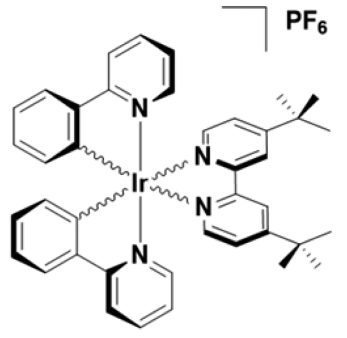

rac-[Ir(ppy) $)_{2}($ dtBubpy) $] P F_{6}$

1a

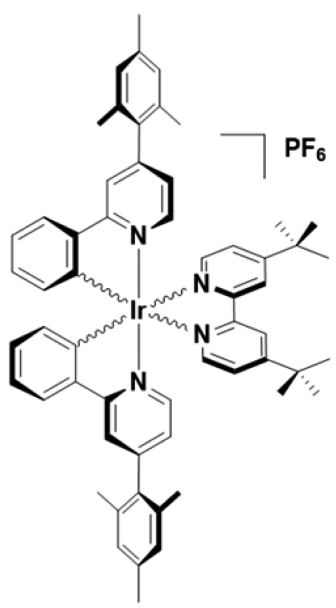

rac- $\left[\operatorname{lr}(\text { ppymes })_{2}(\right.$ dtBubpy $\left.)\right] P F_{6}$

b)

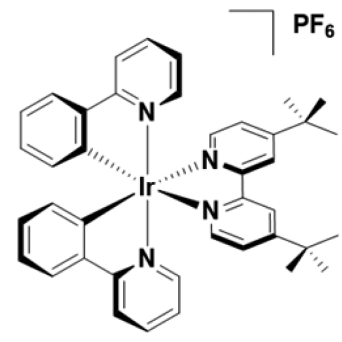

$\Lambda$-[Ir(ppy) $)_{2}($ dtBubpy) $] \mathrm{PF}_{6}$ 1b

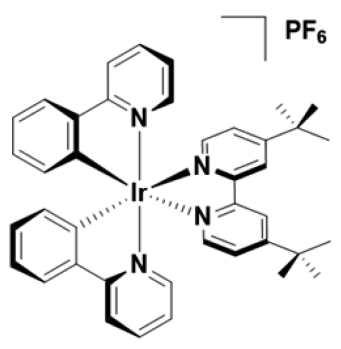

$\Delta$-[Ir(ppy) $\left.{ }_{2}(\mathrm{dtBubpy})\right] \mathrm{PF}_{6}$ 1c

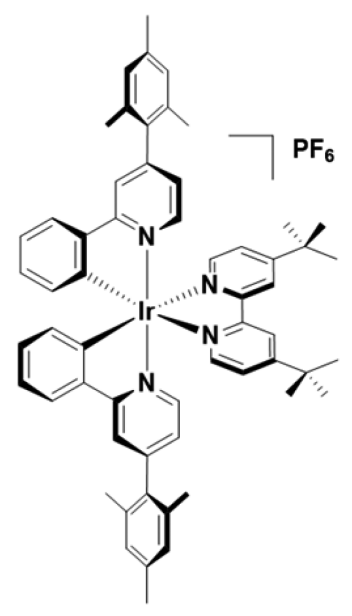

$\Lambda$-[Ir(ppymes) ${ }_{2}($ dtBubpy) $] \mathrm{PF}_{6}$

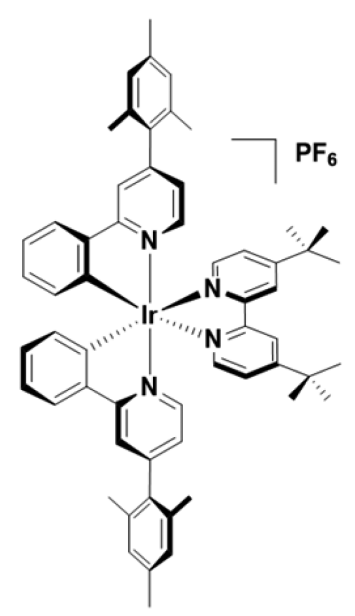

$\Delta$-[Ir(ppymes) ${ }_{2}$ (dtBubpy) $] \mathrm{PF}_{6}$

2b 2c

a)

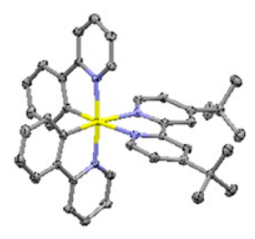

$1 b$

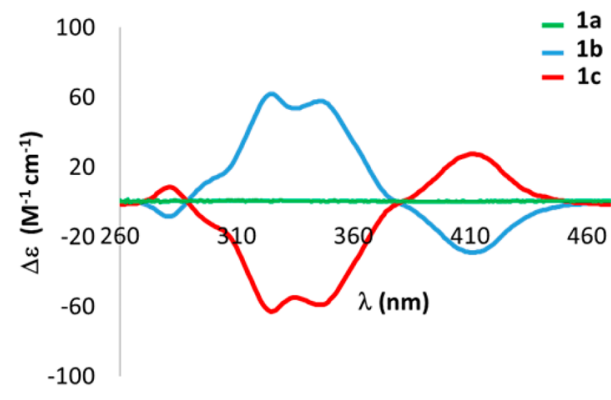

b)

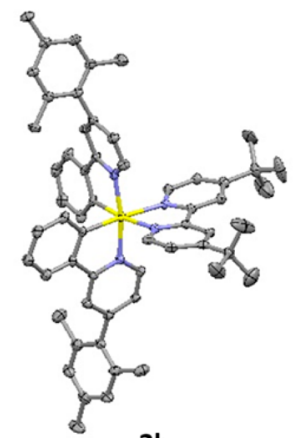

$2 b$

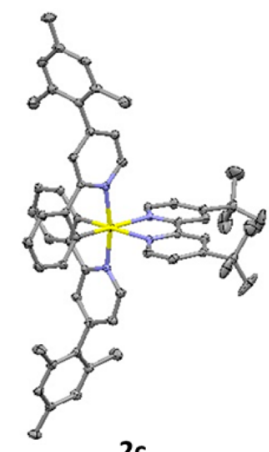

2c

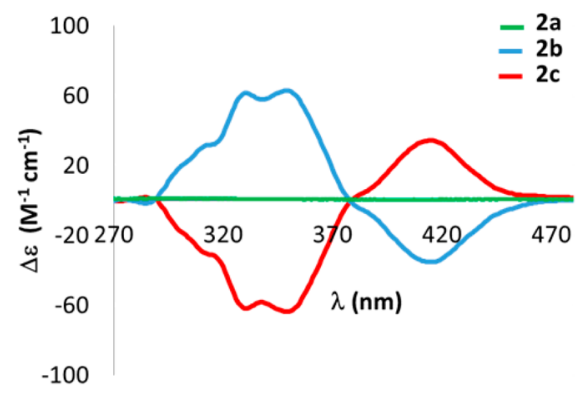

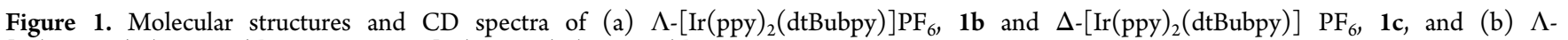
$\left[\operatorname{Ir}(\text { mesppy })_{2}(\mathrm{dtBubpy})\right] \mathrm{PF}_{6}, \mathbf{2 b}$ and $\Delta$-[Ir(mesppy $\left.)_{2}(\mathrm{dtBubpy})\right] \mathrm{PF}_{6}, \mathbf{2 c}$. Hydrogen atoms, $\mathrm{PF}_{6}{ }^{-}$counterions, additional independent molecules of complex and solvent molecules have been omitted for clarity. CD spectra were collected in DCM at $298 \mathrm{~K}$ at a concentration of $1 \times 10^{-5} \mathrm{M}$. Green lines: CD spectra of (a) 1a and (b) 2a; light-blue lines: CD spectra of (a) $\mathbf{1 b}$ and (b) 2b; red lines: CD spectra of (a) 1c and (b) 2c. 

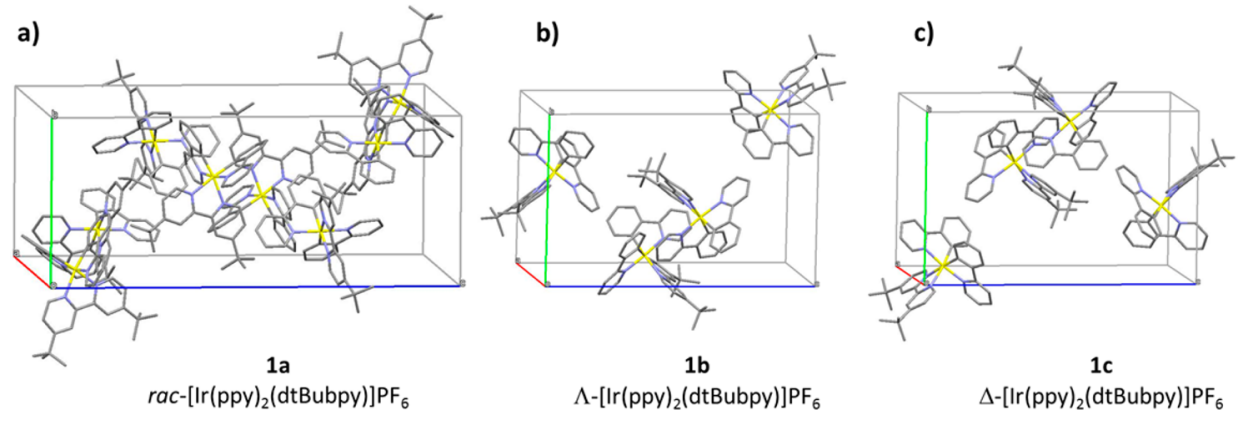

Figure 2. Views of the unit cells (whole molecules shown only) of (a) rac- $\left[\operatorname{Ir}(\mathrm{ppy})_{2}(\mathrm{dtBubpy})\right] \mathrm{PF}_{6}, \mathbf{1 a} ;(\mathrm{b}) \Lambda$ - $\left[\operatorname{Ir}(\mathrm{ppy})_{2}(\mathrm{dtBubpy})\right] \mathrm{PF}_{6}, \mathbf{1} \mathbf{b}$; and $(\mathrm{c})$ $\Delta$ - $\left[\operatorname{Ir}(\mathrm{ppy})_{2}(\mathrm{dtBubpy})\right] \mathrm{PF}_{6}, \mathbf{1 c}$. Hydrogen atoms, $\mathrm{PF}_{6}{ }^{-}$counterions, and solvent molecules are omitted for clarity.
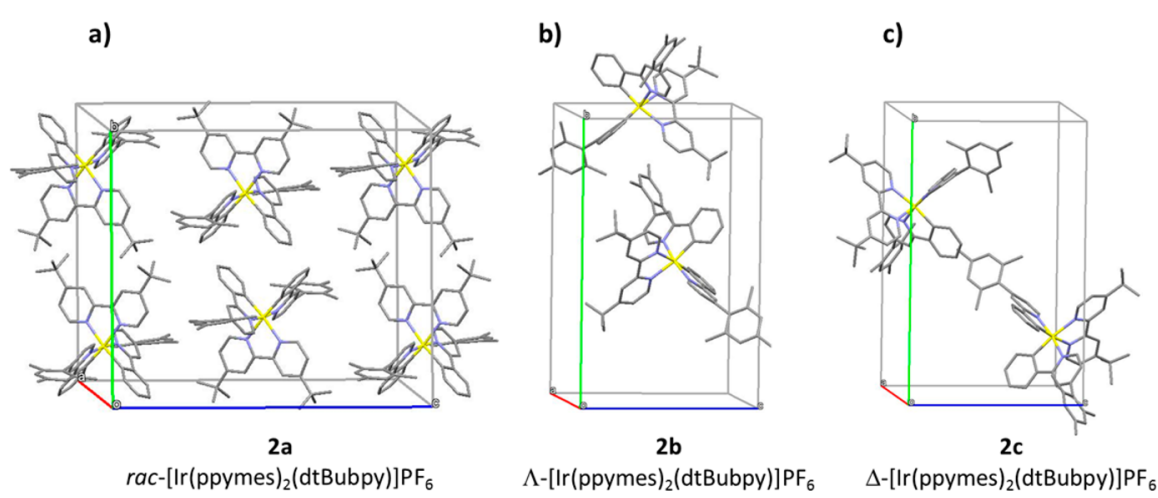

Figure 3. Views of the unit cells (whole molecules shown only) of (a) rac-[Ir(mesppy) $\left.)_{2}(\operatorname{dtBubpy})\right] \mathrm{PF}_{6}, \mathbf{2 a} ;(\mathbf{b}) \Lambda$-[Ir(mesppy) $\left.{ }_{2}(\mathrm{dtBubpy})\right] \mathrm{PF}_{6}, \mathbf{2} \mathbf{b}$; (c) $\Delta$ - $\left[\operatorname{Ir}(\text { mesppy })_{2}(\mathrm{dtBubpy})\right] \mathrm{PF}_{6}, 2 \mathrm{c}$. Hydrogen atoms, $\mathrm{PF}_{6}{ }^{-}$counterions and solvent molecules are omitted for clarity.

using tailored chiral bidentate ligands, such as simple amino acids, ${ }^{25,26}$ salicyloxazolines, salicylthiazolines, ${ }^{10,11,27}$ or prolines ${ }^{28}$ have been reported. Such auxiliaries can transfer their chiral information to an octahedral-metal center and can be subsequently removed tracelessly with retention of the metalcentered absolute configuration. Despite the hundreds of examples of cationic iridium complexes as emitters in LEECs since the first example of their use in $2004^{3}$ and the importance packing in the emissive layer plays in these EL devices, we are not aware of any study that has probed the importance of the metal-centered stereochemistry on the performance of the device.

Herein we report the synthesis, the crystal structures, and the solid-state photophysical properties of two families of iridium(III) complexes of the form of $\left[\operatorname{Ir}\left(\mathrm{C}^{\wedge} \mathrm{N}\right)_{2}(\mathrm{dtBubpy})\right] \mathrm{PF}_{6}$ (where $\mathrm{C}^{\wedge} \mathrm{N}$ is ppy $=2$-phenylpyridinato in 1 , mesppy $=2$ phenyl-4-mesitylpyridinato in 2 , and dtBubpy is $4,4^{\prime}$-ditertbutyl-2,2'-bipyridine, Chart 1 ) in both their $\Lambda, \Delta$-enantiopure and racemic configurations.

We targeted the family of $\left[\operatorname{Ir}(\mathrm{ppy})_{2}(\mathrm{dtBubpy})\right] \mathrm{PF}_{6}$ complexes given the historic and well-studied behavior of 1a and the potential for its use as a simple archetype to evaluate the effect of the enantiopurity $(\mathbf{1} \mathbf{b}-\mathbf{c})$ on the solid-state photophysical and EL device properties (Chart 1a). ${ }^{3}$ We extended our study to the family of $\left[\operatorname{Ir}(\text { mesppy })_{2}(\mathrm{dtBubpy})\right] \mathrm{PF}_{6}$ complexes (Chart $1 \mathrm{~b}$ ) as mesityl substitution at the 4-position of the pyridine ring of fluorinated analogue dFppy $(2-(4,6-$ difluorophenyl)pyridinato) $\mathrm{C}^{\wedge} \mathrm{N}$ ligands had been previously shown by Bryce and co-workers for $\left[\operatorname{Ir}(\mathrm{dFmesppy})_{2}(\right.$ pic $\left.)\right]$ (where pic is 2-piconilate and dFmesppy is (2-(4,6-difluorophenyl)-4-mesitylpyridinato $)^{29}$ and Rota Martir and coworkers for $\left[\operatorname{Ir}(\mathrm{dFmesppy})_{2}(\mathrm{dppe})\right] \mathrm{PF}_{6}$ (where dppe is 1,2- bis(diphenylphosphino)ethene $)^{30}$ to promote reduced intermolecular interaction and positive impact on devices performance. By contrast, in the crystalline state of [Ir(dFmesppy $\left.)_{2}(\mathrm{dtBubpy})\right] \mathrm{PF}_{6}, \pi$-stacking intermolecular interactions between mesityl rings on adjacent complexes are present, and as a consequence, the $\Phi_{\mathrm{PL}}$ is reduced in neat film compared to MeCN solution or PMMA doped thin film. ${ }^{31}$

LEEC devices have been fabricated using both the enantiopure $\Lambda$ and $\Delta$ complexes $(\mathbf{1 b}, \mathbf{1 c}$ and $\mathbf{2 b}, \mathbf{2 c}$, Chart 1 ) as well as the racemic analogues of both families (1a and $\mathbf{2 a}$, Chart 1), and the effect of the stereochemistry of the iridium complexes on the devices performances have been tested.

Crystal Structures. We were able to grow suitable crystals for X-ray diffraction of the $\Lambda$ and $\Delta$ enantiomers $\mathbf{1 b}, \mathbf{1 c}, \mathbf{2 b}$, and $2 \mathrm{c}$ ( Figure 1) and the racemic mixture 1a (Figure S14). The X-ray structure of $\mathrm{rac}$-[ $\left.\operatorname{Ir}(\text { ppymes })_{2}(\mathrm{dtBubpy})\right] \mathrm{PF}_{6}(2 \mathrm{a}$ in Chart 1) was previously reported by our group. ${ }^{32}$ In addition, the crystal structures of the two $\Lambda, \Lambda$ and $\Delta, \Delta$ $\left[\operatorname{Ir}(\text { ppymes })_{2} \mathrm{Cl}\right]_{2}$ diastereomers were also obtained and the structures shown in Figure S13. The absolute configuration of the metal centers has been unambiguously determined by X-ray crystallography as $\Lambda$ for $\mathbf{1 b}$ and $\mathbf{2 b}$ and $\Delta$ for $\mathbf{1 c}$ and $\mathbf{2 c}$. Additionally, the enantiopurity of the samples has been confirmed by CD spectroscopy (Figure 1).

In a similar manner to other $\left[\operatorname{Ir}\left(\mathrm{C}^{\wedge} \mathrm{N}\right)_{2}\left(\mathrm{~N}^{\wedge} \mathrm{N}\right)\right] \mathrm{PF}_{6}$ complexes, ${ }^{33}$ in all the structures the iridium center adopts a distorted-octahedral geometry with the two nitrogen atoms of the $\mathrm{C}^{\wedge} \mathrm{N}$ ligands mutually trans to each other, and the two nitrogen atoms of the dtbubpy ligand disposed trans with respect to the carbon atoms of the $\mathrm{C}^{\wedge} \mathrm{N}$ ligands. As expected, identical geometries are obtained between the two pairs of 
enantiomers (see geometrical parameters of complexes $\mathbf{1 a}-\mathbf{c}$ and $\mathbf{2} \mathbf{a}-\mathbf{c}$ in the SI).

Figure 2 illustrates the crystallographic unit cells of $\mathbf{1 a}, \mathbf{1} \mathbf{b}$, and 1c. The racemic complex $1 \mathrm{a}$ crystallizes in the centrosymmetric space group $P 2_{1} / n$ upon $\mathrm{Et}_{2} \mathrm{O}$ diffusion into a 1,2-dichloroethane solution (Figure 2a). Both $\Lambda$ and $\Delta$ $\left[\operatorname{Ir}(\text { ppy })_{2}(\mathrm{dtBubpy})\right] \mathrm{PF}_{6}$ enantiomers $\mathbf{1 b}$ and $\mathbf{1 c}$ crystallize in the Sohncke space group $P 2_{1} 2_{1} 2_{1}$ upon $\mathrm{Et}_{2} \mathrm{O}$ diffusion into DCM solutions (Figure $2 \mathrm{~b}, \mathrm{c}$, respectively). By contrast, the racemic mixture 1a shows a unit cell populated by equal amounts of both $\Lambda$ and $\Delta$ enantiomers, where the molecules pack such that layers of molecules of the same enantiomer form in the $\left(\begin{array}{lll}1 & 0 & 0\end{array}\right)$ plane, and where molecules of the same

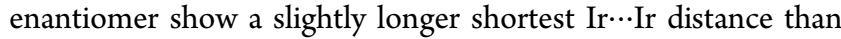
molecules of different enantiomers [7.9098(9) Å and 7.8973(9) $\AA$, respectively].

A similar trend can be observed for the family of $\left[\operatorname{Ir}(\text { mesppy })_{2}(\mathrm{dtBubpy})\right] \mathrm{PF}_{6}$ complexes (Figure 3 ). The racemate 2 a crystallized in the centrosymmetric space group $I 2 /$ a, and the two enantiomers $\mathbf{2 b}$ and $\mathbf{2 c}$ crystallized in the Sohncke space group $P 2_{1}$ giving rise again to two unit cells related by inversion through the origin (Figure $2 b, c)$. In contrast to the layered packing mode seen in $\mathbf{1 a}$, the packing in the structure of racemic $2 a$ shows a motif of alternating adjacent $\Lambda$ and $\Delta$ enantiomers (Figure 3 a). Again, the shortest Ir $\cdots$ Ir distance for molecules of the same enantiomer is greater than that for molecules of differing enantiomers, although in this case, the difference is more pronounced [11.8361(13) $\AA$ and 9.8691(7) $\AA$, respectively].

The molecular packing in the solid state in all the complexes is built up from a variety of weaker interactions. None of the complexes, in either enantiopure or racemic structures, show strong intermolecular interactions, such as $\pi-\pi$ stacking, in contrast to previously reported fluorinated analogue complexes. ${ }^{31}$ The three structures of $\mathbf{1}$ all show very few intermolecular interactions between complex cations but more interactions between cation and anion. In the racemic 1a, edge-to-face $\mathrm{CH} \cdots \pi$ interactions are seen $[\mathrm{H} \cdots$ centroid distance $2.83 \AA$, C...centroid distance $3.684(14) \AA]$, forming loosely interacting molecular dimers. These are linked together through weak $\mathrm{CH} \cdots \mathrm{F}$ hydrogen bonds to the $\mathrm{PF}_{6}{ }^{-}$anions $[\mathrm{H} \cdots$ F distances 2.36-2.51 Å; C...F distances 3.122(13)-3.386(14) $\AA]$, forming bilayer sheets in the (101) plane. The structure does pack with space available for included solvent molecules in channels running along the $b$-axis; however, probably due to solvent loss on handling the crystals, no solvent could be located in these channels. In contrast, both the enantiopure complexes $\mathbf{1 b}$ and $\mathbf{1 c}$ do not show the $\mathrm{CH} \cdots \pi$ interaction, but they do show a similar formation of a weakly hydrogen-bonded bilayers, mediated by $\mathrm{PF}_{6}{ }^{-}$anions $[\mathrm{H} \cdots \mathrm{F}$ distances: $1 \mathbf{b}$ 2.31$2.45 \AA$, 1c 2.29-2.55 $\AA$; C C..F distances: 1b 3.019(9)3.401(12) A, 1c 3.005(9)-3.436(10) $\AA$, in the (001) plane. These two structures also show narrow solvent channels, again running along the $b$-axis, containing the included dichloromethane solvent. None of the structures of 1 show any significant interactions between bilayer sheets. The three structures of 2 in turn show a different set of intermolecular interactions. In the racemic $2 \mathrm{a}$, edge-to-face $\mathrm{CH} \cdots \pi$ interactions are seen $[\mathrm{H} \cdots$ centroid distance $2.88 \AA$, C $\cdots$ centroid distance 3.429(3) §], forming loosely interacting molecular dimers. These are linked together through weak $\mathrm{CH} \cdots \mathrm{F}$ hydrogen bonds to the $\mathrm{PF}_{6}{ }^{-}$anions $[\mathrm{H} \cdots \mathrm{F}$ distances $2.50-2.53 \AA$; $\mathrm{C} \cdots \mathrm{F}$ distances $3.268(3)-3.451(2) \AA]$, forming double chains running along the $a$-axis. Like 1a, 2a does not contain solvent; however, it does not contain sufficient contiguous void space to contain solvent molecules, either. The total free space of $233 \AA^{3}$ arises from a combination of a number of smaller voids, likely arising from packing inefficiencies, scattered throughout the structure. The intermolecular interactions in enantiopure $\mathbf{2 b}$ and $2 \mathrm{c}$ are, in contrast, different to those seen in any of the structures of $\mathbf{1}$ and in racemic $\mathbf{2 a}$. The cationic complexes form a network of multiple $\mathrm{CH} \cdots \pi$ interactions [H...centroid

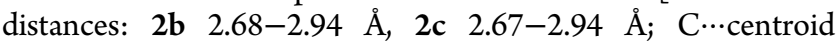
distances: 2b 3.447(9)-3.861(11) $\AA$, 2c 3.443(5)-3.855(7) $\AA$ ], leading to the formation of two-dimensional sheets in the (001) plane. Surprisingly, the $\mathrm{PF}_{6}{ }^{-}$anions in $\mathbf{2 b}$ and $2 \mathbf{c}$ do not form any weak hydrogen bonds to the cations, but rather, they bond to the diethyl ether solvent molecules via further weak $\mathrm{CH} \cdots \pi$ interactions to the cations. As was the case in $\mathbf{2 a}, \mathbf{2} \mathbf{b}$ and $2 \mathrm{c}$ both show small packing inefficiencies, despite included solvent molecules, leading to some residual void space (2b: 56 $\left.\AA^{3}, 2 \mathrm{c}: 42 \AA^{3}\right)$. The presence of the intermolecular interactions within the structures, as well as the size and shape of the complex cations themselves given rise a range of shortest $\mathrm{Ir} \cdots \mathrm{Ir}$ distances in $\mathbf{1}$ and $\mathbf{2}$, the distances for $\mathbf{2}$ being greater than those for 1 . In the case of both complexes, the enantiopure structures show almost identical separations: $8.4281(5)$ and

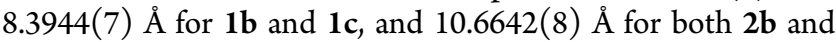
$2 c$. In both the racemic complexes $1 \mathbf{a}$ and $\mathbf{2 a}$, the Ir $\cdots$ Ir distance for the $\Lambda$-form to the $\Delta$-form is shorter than the distances seen in the enantiopure complexes; 7.8973(9) $\AA$ for $\mathbf{1 a}$ and

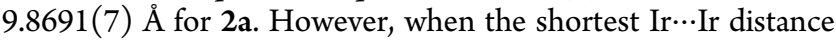
between complexes of the same stereochemistry within the racemic structure is considered, in 1a this distance is still shorter than the equivalent contact in $\mathbf{1 b}$ or $\mathbf{1 c}$, at $7.9098(9) \AA$, but in $\mathbf{1 b}$ this distance is the longest $\operatorname{Ir} \cdots \operatorname{Ir}$ separation seen in any of the six structures, at 11.8361(13) A.

Importantly, as a result of the similar solid-state interactions in the crystal packing of both pair of enantiomers of both families 1 and 2, very similar solid-state photophysical properties are observed between the enantiomers $\mathbf{1 b}, \mathbf{1 c}$ and $\mathbf{2 b}, \mathbf{2 c}$. By contrast, the different crystal packing found for each of the two racemates $\mathbf{1 a}$ and $\mathbf{2 a}$ promote divergent solid-state properties compared to their enantiopure analogues (Table 1).

Photophysical Investigation. The optoelectronic properties of $1 \mathbf{a}-\mathbf{c}$ and $\mathbf{2 a}-\mathbf{c}$ have been investigated in DCM solution and as spin-coated neat thin films and are summarized in Table 1. Upon excitation with unpolarised light, the absorption spectra of $1 \mathbf{a}-\mathbf{c}$ and $2 a-c$ match with those previously reported for $\mathbf{1} \mathbf{a}^{34}$ and $\mathbf{2 a}$. $^{32}$ As expected, no differences in the absorption properties between enantiopure and racemic analogues were observed (Figure S15 and S16).

In DCM solution, the emission properties of the enantiomers $\mathbf{1 b}, \mathbf{1 c}$ and $\mathbf{2 b}, \mathbf{2 c}$ match, respectively, those of their racemic analogues $\mathbf{1 a}$ and $\mathbf{2 a}$, as would be expected (Table 1, Figure 4); the photophysical properties of 1a in DCM solution also match those previously reported. ${ }^{34}$ The solution emission maximum of $\mathbf{2}$ is not affected by the presence of the mesityl group, which is disposed in a nearly orthogonal and locked conformation with respect to the plane of the pyridine ring (Figure 1). ${ }^{29-31}$ Thus, for 1 and 2, the same $\lambda_{\mathrm{em}}$ at $577 \mathrm{~nm}$ is observed (Table 1).

Differences of the emission properties between enantiomerically pure and racemic materials arise in the solid state. As shown in Figure 4a, the neat film emission of the racemate 1a is blue-shifted $\left(\lambda_{\mathrm{em}}=560 \mathrm{~nm}\right)$ compared to the emission of the $\Lambda$ 
Table 1. Relevant Photophysical Data for $1 a-c$ and $2 a-c$

\begin{tabular}{|c|c|c|c|c|c|c|}
\hline & \multicolumn{2}{|c|}{$\lambda_{\mathrm{em}}(\mathrm{nm})^{a, b}$} & \multicolumn{2}{|c|}{$\Phi_{\mathrm{PL}}(\%)^{d}$} & \multicolumn{2}{|c|}{$\tau_{\mathrm{e}}(\mathrm{ns})^{a}$} \\
\hline & $\mathrm{DCM}^{a}$ & film $^{b, c}$ & $\mathrm{DCM}^{d}$ & film ${ }^{c, e}$ & DCM & film $^{c_{2} f}$ \\
\hline 1a & 577 & 560 & 35 & 38.0 & 877 & $\begin{array}{c}455(0.30) \\
779(0.70)\end{array}$ \\
\hline $1 b$ & 577 & 582 & 34 & 31.3 & 811 & $\begin{array}{l}58(0.05), \\
322(0.35) \\
693(0.70)\end{array}$ \\
\hline 1c & 577 & 582 & 34 & 29.8 & 811 & $\begin{array}{l}42(0.04), \\
291(0.29), \\
698(0.60)\end{array}$ \\
\hline $2 a$ & 577 & $\begin{array}{c}478(0.6) \\
516(0.9) \\
550(1)\end{array}$ & 40 & 18.2 & 757 & $\begin{array}{l}25(0.06), \\
211(0.42), \\
672(0.52)\end{array}$ \\
\hline $2 b$ & 577 & $\begin{array}{l}480(0.8) \\
511(1)\end{array}$ & 41 & 39.8 & 765 & $\begin{array}{c}405(0.47) \\
923(0.53)\end{array}$ \\
\hline $2 c$ & 577 & $\begin{array}{c}479(0.8) \\
511(1)\end{array}$ & 41 & 40.7 & 765 & $\begin{array}{c}411(0.47) \\
940(0.53)\end{array}$ \\
\hline
\end{tabular}

${ }^{a}$ Measurements in degassed DCM at $298 \mathrm{~K}\left(\lambda_{\mathrm{ex}}=360 \mathrm{~nm}\right) .{ }^{b}$ Principal emission peaks listed with values in parentheses indicating relative intensity $\left(\lambda_{\text {exc }}=378 \mathrm{~nm}\right) .{ }^{c}$ Thin films formed by spin-coating on a pristine quartz substrate. ${ }^{d} \Phi_{\mathrm{PL}}$ measurements were carried out in degassed DCM under nitrogen $\left(\lambda_{\text {exc }}=360 \mathrm{~nm}\right)$ using quinine sulfate as the external reference $\left(\Phi_{\mathrm{PL}}=54.6 \%\right.$ in $0.5 \mathrm{M} \mathrm{H}_{2} \mathrm{SO}_{4}$ at $298 \mathrm{~K}^{35}$ ${ }^{e}$ Values obtained using an integrating sphere. ${ }^{f}$ Values in parentheses are pre-exponential weighting factor, in relative \% intensity, of the emission decay kinetics $\left(\lambda_{\mathrm{exc}}=378 \mathrm{~nm}\right)$.

and $\Delta$ enantiomers $\mathbf{1 b}$ and $\mathbf{1 c}$, both of which emit at $\lambda_{\mathrm{em}}=582$ $\mathrm{nm}$. The racemate 1a showed a higher $\Phi_{\mathrm{PL}}$ of $38.0 \%$ coupled with a longer biexponential emission lifetime $\left(\tau_{\mathrm{e}}=455 \mathrm{~ns}, 779\right.$ $\mathrm{ns)}$ compared to $\mathbf{1 b}$ and $\mathbf{1 c}$, both of which showed nearly identical photophysical properties and multiexponential decay kinetics (for 1b: $\Phi_{\mathrm{PL}}=31.3 \%$ and $\tau_{\mathrm{e}}=58 \mathrm{~ns}, 157 \mathrm{~ns}, 644 \mathrm{~ns}$; for 1c: $\Phi_{\mathrm{PL}}=29.8 \%$ and $\tau_{\mathrm{e}}=42 \mathrm{~ns}, 173 \mathrm{~ns}, 622 \mathrm{~ns}$, Table 1).

Divergent solid-state photophysical properties between the racemate $\mathbf{2} \mathbf{a}$ and the enantiomers $\mathbf{2 b}$ and $\mathbf{2 c}$ are also observed (Table 1). Indeed, the broad emission profile at ca. $550 \mathrm{~nm}$ of the racemate $\mathbf{2 a}$ is distinct compared to the more structured and blue-shifted emission $\left(\lambda_{\mathrm{em}}=480\right.$ and $\left.511 \mathrm{~nm}\right)$ present for the enantiomers $\mathbf{2 b}$ and $\mathbf{2 c}$ (Figure $4 \mathrm{~b}$ ). Furthermore, the $\Phi_{\mathrm{PL}}$ of $18.2 \%$ for $2 \mathrm{a}$ in the solid-state is considerably lower than that for $2 \mathbf{b}\left(\Phi_{\mathrm{PL}}=39.8 \%\right)$ and $2 \mathrm{c}\left(\Phi_{\mathrm{PL}}=40.7 \%\right)$. The multiexponential emission lifetime for $2 \mathrm{a}$ of $25,211,672 \mathrm{~ns}$ is significantly shorter than the biexponential emission lifetime behavior determined for $\mathbf{2 b}\left(\tau_{\mathrm{e}}=405 \mathrm{~ns}, 923 \mathrm{~ns}\right)$ and $\mathbf{2 c}\left(\tau_{\mathrm{e}}=\right.$ $411 \mathrm{~ns}, 940 \mathrm{~ns})$. The solid-state lifetime decays are illustrated in Figure S19 - S23 in the ESI.

From the emission properties of both families of complexes 1 and 2, the species that emits at higher energy (1a for family $\mathbf{1}$ and both enantiomers $\mathbf{2 b}$ and $\mathbf{2 c}$ for family 2 ) also show the highest $\Phi_{\mathrm{PL}}$ and the longest average $\tau_{\mathrm{e}}$. However, no consistent correlation between these properties and the crystal packing of these materials has been observed. Indeed, for both family of complexes, the racemates $\mathbf{1 a}$ and $\mathbf{2 a}$ show the shortest $\mathrm{Ir} \cdots \mathrm{Ir}$ intermolecular distances (7.8973(9) $\AA$ for 1a and 9.8691(7) $\AA$ for 2a) compared to the corresponding enantiopure analogues 1b, 1c and 2b, 2c (respectively, 8.4281(5) and 8.3944(7) A for $\mathbf{1 b}$ and $\mathbf{1 c}$ and $10.6642(8) \AA$ for both $2 \mathrm{~b}$ and $2 \mathrm{c}$ ). While for $\mathbf{1 a}$, a slightly blue-shifted emission with higher $\Phi_{\mathrm{PL}}$ is observed compared to $\mathbf{1 b}$ and $\mathbf{1 c}$, the opposite behavior is noted for the racemate $\mathbf{2 a}$, where its emission is red-shifted and lower in intensity compared to both enantiomers $\mathbf{2 b}$ and $\mathbf{2 c}$ (Table 1 ). It is worth pointing out that the neat films of $\mathbf{1}$ and $\mathbf{2}$ were prepared by spin-coating deposition from a 2-methoxyethanol solution of the samples and therefore differences in the packing found in the single crystals and the amorphous films may account for the differences observed between the two families of complexes.

Light-Emitting Electrochemical Cells. Double-layer LEEC devices have been prepared using the racemic and the $\Lambda$ and $\Delta$ enantiomers from both families of complexes. Devices were prepared on cleaned patterned glass-ITO (indium tin oxide) substrates elaborated with a spin-coated, thin layer (80 $\mathrm{nm}$ ) of poly(3,4-ethylenedioxythiophene):polystyrenesulfonate (PEDOT:PSS). On top of this a $100 \mathrm{~nm}$ thick complex:ionic liquid (IL) (4:1 molar ratio) film has been deposited from an acetonitrile solution $\left(20 \mathrm{mg} \cdot \mathrm{mL}^{-1}\right)$, where the IL employed is 1-butyl-3-methylimidazolium hexafluorophosphate [BMIM]$\left[\mathrm{PF}_{6}\right]$. The IL was added to reduce the turn-on time of the LEEC due to the increase in the concentration of ionic species and the ionic mobility. ${ }^{36,37}$ The substrates were annealed under an $\mathrm{N}_{2}$ atmosphere at $100{ }^{\circ} \mathrm{C}$ over $1 \mathrm{~h}$. Thermal evaporation of a $70 \mathrm{~nm}$ thick aluminum electrode under a base pressure of $2 \times$ $10^{-6}$ mbar completes the device. LEECs fabricated with the complexes $\mathbf{1 a}-\mathbf{c}$ and $\mathbf{2 a}-\mathbf{c}$ will be referred from now as LEECs $\mathbf{1 a}-\mathbf{c}$ and $\mathbf{2 a - c}$, respectively. For each device configuration at
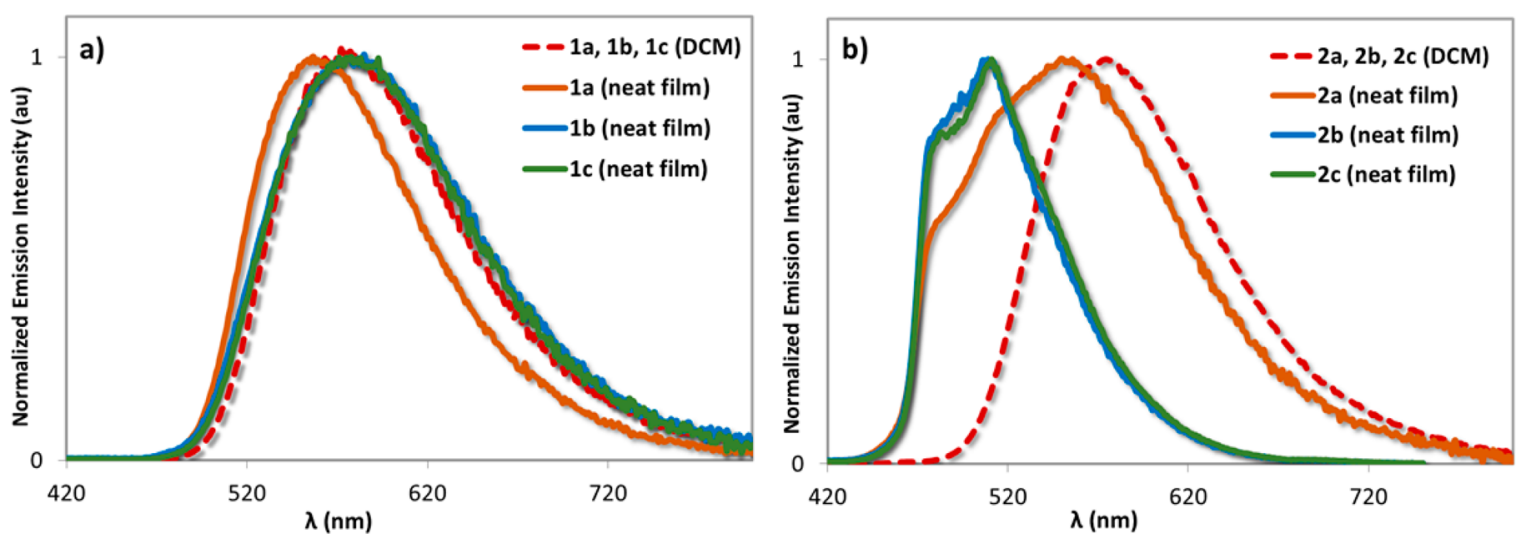

Figure 4. Dotted red lines: normalized photoluminescence spectra of (a) $\mathbf{1 a}, \mathbf{1} \mathbf{b}$, and $\mathbf{1 c}$ and (b) $\mathbf{2 a}$, 2b, and $\mathbf{2 c}$ recorded in degassed DCM at $298 \mathrm{~K}$; solid orange lines: normalized solid-state photoluminescence spectra of (a) 1a and (b) 2a; solid light-blue lines: normalized solid-state photoluminescence spectra of (a) $\mathbf{1 b}$ and (b) $2 \mathbf{b}$; solid green lines: normalized solid-state photoluminescence spectra of (a) 1c and (b) 2c. All of the solid-state measurements were collected at $298 \mathrm{~K}$ on films formed by spin-coating deposition on pristine quartz substrate. 

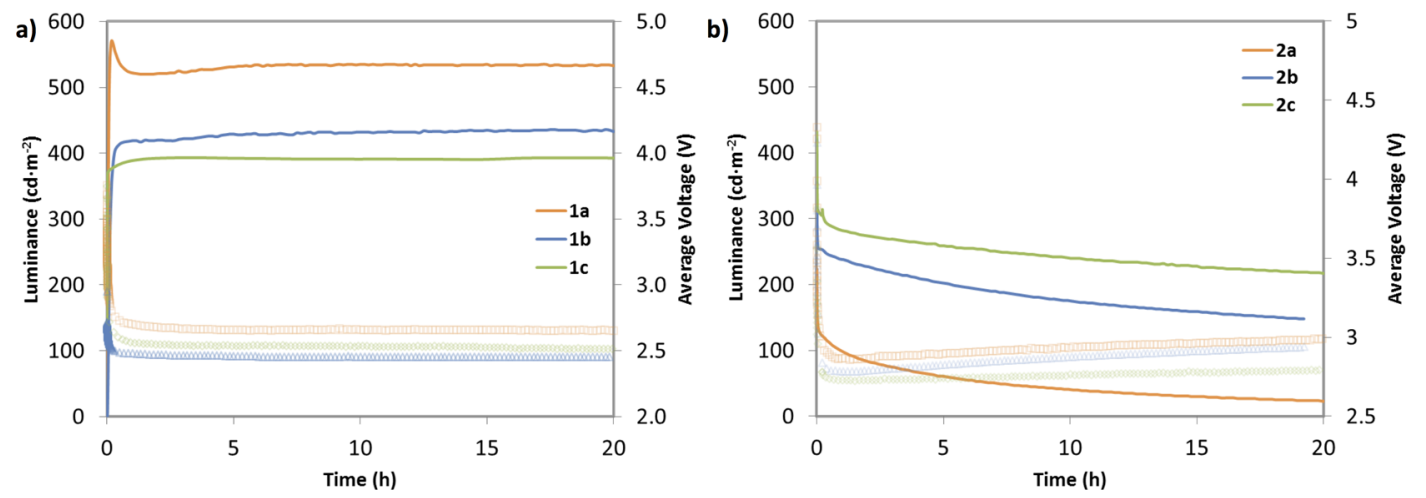

Figure 5. Time-dependent luminance (solid line) and operating voltage (dashed line) data of LEECs driven under pulsed-current operation with an average current density of $50 \mathrm{~A} \cdot \mathrm{m}^{-2}(1000 \mathrm{~Hz}, 50 \%$ duty cycle, block wave) using complexes (a) 1a-c and (b) 2a-c as emitters. Note for compound numbering: (a) racemic; (b) $\Lambda$ enantiomer, (c) $\Delta$ enantiomer.

Table 2. LEECs Performances Data under Pulsed-Current Operation (Average Current Density $50 \mathrm{~A} \cdot \mathrm{m}^{-2}, 1000 \mathrm{~Hz}, 50 \% \mathrm{Duty}$ Cycle, Block Wave)

\begin{tabular}{|c|c|c|c|c|c|c|c|c|}
\hline $\operatorname{lum}_{\mathrm{o}}{ }^{a}\left(\mathrm{~cd} \cdot \mathrm{m}^{-2}\right)$ & $\operatorname{lum}_{\max }^{b}\left(\mathrm{~cd} \cdot \mathrm{m}^{-2}\right)$ & $t_{\mathrm{on}}^{c}(\mathrm{~s})$ & $t_{1 / 2}^{d}(\mathrm{~h})$ & $\begin{array}{l}\mathrm{EQE}_{\max }{ }^{e} \\
(\%)\end{array}$ & efficacy $_{\max }\left(\mathrm{cd} \cdot \mathrm{A}^{-1}\right)$ & $\mathrm{PE}_{\max }{ }^{f}\left(\mathrm{~lm} \cdot \mathrm{W}^{-1}\right)$ & $\lambda_{\mathrm{EL}, \max }(\mathrm{nm})$ & $\mathrm{CIE}^{g}$ \\
\hline 1a & 571 & 80 & $>1300^{h}$ & 3.5 & 11.0 & 6.6 & 575 & $\begin{array}{r}(0.4898, \\
0.5021)\end{array}$ \\
\hline $1 b$ & 435 & 200 & $>700^{h}$ & 2.8 & 8.7 & 5.6 & 573 & $\begin{array}{c}(0.4809 \\
0.5095)\end{array}$ \\
\hline 117 & 394 & $<2$ & $>400^{h}$ & 2.6 & 8.0 & 5.0 & 574 & $\begin{array}{r}(0.4820 \\
0.5091)\end{array}$ \\
\hline 218 & 224 & $<2$ & 0.6 & 1.4 & 4.3 & 1.8 & 572 & $\begin{array}{r}(0.4715 \\
0.5166)\end{array}$ \\
\hline 398 & 398 & $<2$ & 5.2 & 2.5 & 7.4 & 3.1 & 574 & $\begin{array}{r}(0.4718 \\
0.5122)\end{array}$ \\
\hline 423 & 432 & $<2$ & 22.0 & 2.7 & 8.7 & 3.9 & 568 & $\begin{array}{c}(0.4568 \\
0.5293)\end{array}$ \\
\hline
\end{tabular}

${ }^{a}$ Initial luminance. ${ }^{b}$ Maximum luminance reached. ${ }^{c}$ Time to reach $100 \mathrm{~cd} \cdot \mathrm{m}^{-2}$ luminance. ${ }^{d}$ Time to reach one-half of the maximum luminance. ${ }^{e}$ Maximum external quantum efficiency reached. ${ }^{f}$ Maximum power efficiency reached. ${ }^{g}$ The Commission Internationale de $1^{\prime}$ Eclairage (CIE) color coordinates. ${ }^{h}$ Extrapolated values.

least two substrates each containing 4 individual cells were evaluated, ensuring a statistically relevant analysis.

The luminance and voltage vs time dependence of the LEECs $\mathbf{1 a}-\mathbf{c}$ and $\mathbf{2 a}-\mathbf{c}$ are shown in Figure 5a,b. Performance metrics for these devices are summarized in Table 2. Both families present different characteristics under pulsed-current density driving but all devices exhibit the typical LEEC behavior: the luminance increases until a maximum is reached and then starts to decrease while the operating voltage rapidly decays at the beginning of operation, reaching a minimum at values in the range of $2.4-2.7 \mathrm{~V}$, indicating that the barrier for electron and hole injection is effectively removed by the ion migration. Interestingly, once this state is achieved, the voltage follows different behavior depending on the family of complexes incorporated in the device. The LEECs 1a-c show a constant steady-state voltage whereas the LEECs $2 a-c$ show a slow increase of the voltage. This increase of the layer resistance could be an indication of chemical degradation under operation. ${ }^{38}$ The turn-on time $\left(t_{\text {on }}\right)$ of the devices, defined as the time to reach $100 \mathrm{~cd} \cdot \mathrm{m}^{-2}$ luminance, is near instantaneous $(<2 \mathrm{~s}$ ) except for LEECs $\mathbf{1} \mathbf{a}$ and $\mathbf{1} \mathbf{b}$, where turn-on times vary from 80 to $200 \mathrm{~s}$, respectively. The time required to reach 100 $\mathrm{cd} \cdot \mathrm{m}^{-2}$ luminance is likewise strongly complex-dependent. Despite containing less mobile complexes due to their larger size, LEECs $\mathbf{2 a}-\mathbf{c}$ show faster response than LEECs $\mathbf{1 a}-\mathbf{c}$. This behavior is attributed to the presence of the mesityl substituents, which induce a more efficient electronic communication and more rapid charge hoping and recombination kinetics, resulting in faster turn-on time for the devices fabricated using complexes $\mathbf{2 a - c}$.

The lifetime $\left(t_{1 / 2}\right)$, defined as the time to reach one-half of the maximum luminance, is used to evaluate the device stability. The LEECs fabricated with $\mathbf{1 a - c}$ are more stable with significantly higher lifetime compared to the LEECs based on the family $2 \mathbf{a}-\mathbf{c}$. At this point, it is worth highlighting that the $t_{1 / 2}$ could not be determined during the lifetime test of the LEECs 1a-c. However, an estimated lifetime value can be determined by extrapolation, thereby obtaining $t_{1 / 2}$ longer than $1300 \mathrm{~h}$ for device $1 \mathrm{a}, 700 \mathrm{~h}$ for $1 \mathrm{~b}$, and $400 \mathrm{~h}$ for $1 \mathrm{c}$. A direct comparison with previous LEECs reported for complex 1a is complicated due to the driving mode used in this work. Pulsedcurrent driving is well-known to improve the device stability with respect to traditional constant-voltage driving. The lifetime found here for the LEEC 1a is in the same range to other very stable and efficient orange LEECs with lifetimes ranging from 2000 to 3000 h. $^{39,40}$ In the case of devices $2 \mathbf{a}-\mathbf{c}$, the lifetime follows the opposite trend. The lifetime for $2 \mathrm{a}$ is less than $1 \mathrm{~h}$, for $\mathbf{2 b}$ it is $5.2 \mathrm{~h}$, and $2 \mathrm{c}$ it is $22 \mathrm{~h}$. The lifetime differences observed here could be understood by the device response and voltage behavior described above. On the one hand, the faster response of LEECs $2 a-c$ leads to a faster growth of the doped regions, which increase the exciton-quenching efficiency over time. On the other hand, the increase of the voltage over time of devices $\mathbf{2 a}-\mathbf{c}$ is an indication of material degradation during 

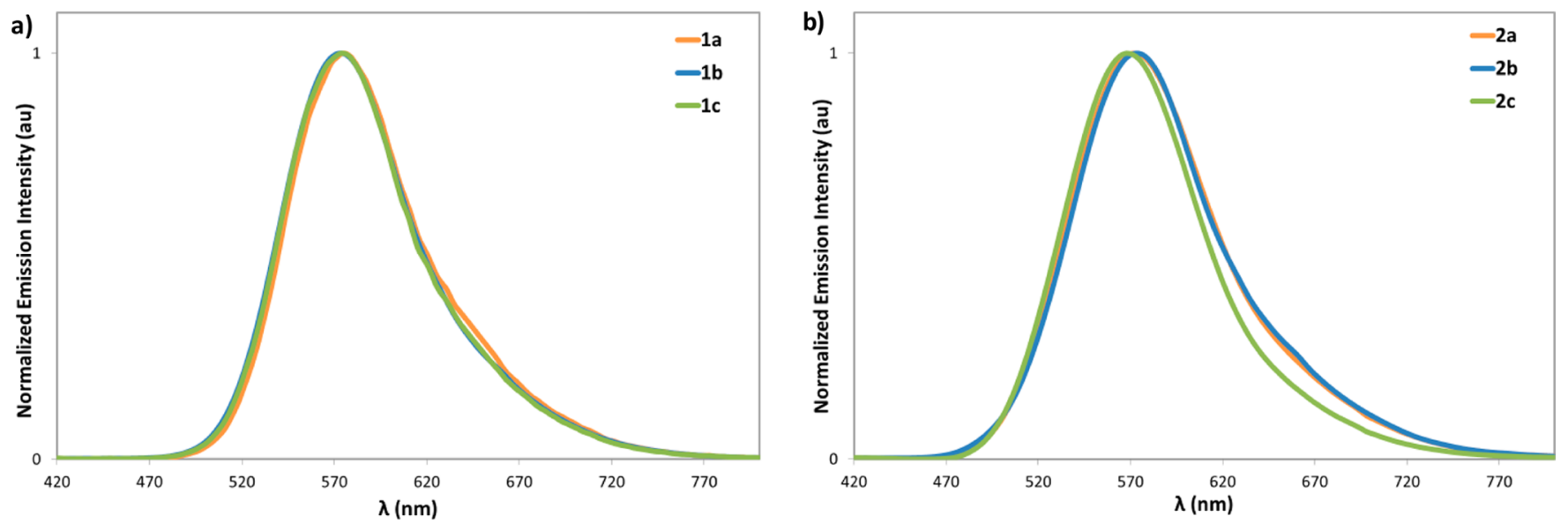

Figure 6. Electroluminescence spectra of LEECs (a) $1 a-c$ and (b) $2 a-c$.

device operation. Hence, both characteristics negatively influence the lifetime of LEECs $\mathbf{2 a}-\mathbf{c}$. The extended timedependent luminance and voltage behavior of LEECs 1a-c until $80 \mathrm{~h}$ are shown in the Figure S25.

A LEEC device was previously prepared by using [Ir$\left.(\mathrm{ppyPh})_{2}(\mathrm{dtBubpy})\right] \mathrm{PF}_{6}$ as the emitter (ppyPh $=2-(3-$ phenylphenyl)pyridinato) where this iridium complex is functionalized with a phenyl ring at the 5-position of the phenyl ring of the $\mathrm{C}^{\wedge} \mathrm{N}$ ligands. ${ }^{41}$ Employing this Ir complex resulted in a very bright and stable device $\left(L_{\max }=1090 \mathrm{~cd} \mathrm{~m}^{-2}\right.$ and $t_{1 / 2}=437 \mathrm{~h}$ ). Thus, the regiochemistry of aryl substitution on the $\mathrm{C}^{\wedge} \mathrm{N}$ ligands has a dramatic effect on the overall device performance.

Interestingly, the LEECs employing the $\Lambda$ and $\Delta$ enantiomers show different device luminance and device efficiency compared to the LEEC using the respective racemic mixtures. LEEC 1a shows a maximum luminance of $570 \mathrm{~cd}$ $\mathrm{m}^{-2}$, which corresponds to an efficacy, power conversion efficiency (PCE), and external quantum efficiency (EQE) of $11.0 \mathrm{~cd} \mathrm{~A}^{-1}, 6.6 \mathrm{~lm} \mathrm{~W}^{-1}$ and $3.5 \%$ respectively. LEECs $\mathbf{1 b}-\mathrm{c}$, by contrast, exhibit lower performance in both cases $(8.7 \mathrm{~cd}$ $\mathrm{A}^{-1}$ at $435 \mathrm{~cd} \mathrm{~m}^{-2}$ and $8.0 \mathrm{~cd} \mathrm{~A}^{-1}$ at $394 \mathrm{~cd} \mathrm{~m}^{-2}$ for device $\mathbf{1 b}$ and $\mathbf{1 c}$, respectively). In the case of LEEC $2 \mathrm{a}$, the maximum luminance is $224 \mathrm{~cd} \mathrm{~m}^{-2}$, which corresponds to an efficacy, PCE and EQE of $4.3 \mathrm{~cd} \mathrm{~A}^{-1}, 1.8 \mathrm{~lm} \mathrm{~W}^{-1}$ and $1.4 \%$, respectively, while LEECs $\mathbf{2 b - c}$ show considerably improvement in performance compared to 2a. Specifically, the efficiency characteristics were $7.4 \mathrm{~cd} \mathrm{~A}^{-1}, 3.1 \mathrm{~lm} \mathrm{\textrm {W } ^ { - 1 }}, 2.5 \%$ for LEEC $\mathbf{2 b}$ and $8.7 \mathrm{~cd} \mathrm{~A}^{-1}, 3.9 \mathrm{~lm} \mathrm{~W}^{-1}, 2.7 \%$ for LEEC 2c. The efficiency trend for each family of complexes is in line with the $\Phi_{\text {PL }}$ obtained for the thin films (Table 1) described above. As the $\Phi_{\mathrm{PL}}$ values in the neat film were somewhat comparable for each pair of enantiomers and significantly different for the racemic mixture, the differences observed should be related to different packing and aggregation in the thin film when comparing pure enantiomers with racemic mixture, despite the addition of IL in the emissive layer of the EL device. However, this effect is rather dependent on the family studied. On the one hand, in view of the lower $\Phi_{\mathrm{PL}}$ of $2 \mathrm{a}$, the presence of the mesityl groups induces in thin film the complex to aggregate more in the racemic mixture compared to the enantiopure compounds $(\mathbf{2} \mathbf{b}, \mathbf{c})$. On the other hand, for the family $\mathbf{1 a}-\mathbf{c}$, the enantiopure compounds $(\mathbf{1 b}, \mathbf{c})$ show in thin film a higher predisposition to aggregate, suggested by their lower $\Phi_{\mathrm{PL}}$. These observations are also supported by the differences in the photoluminescence emission discussed above (Figure 4 and Table 1), where the complex $\mathbf{1} \mathbf{b}, \mathbf{c}$ as well as $\mathbf{2 a}$ show a redshifted emission with respect to $\mathbf{1 a}$ and $\mathbf{2 b}, \mathbf{c}$, respectively.

The electroluminescence (EL) spectra are depicted in Figure 6. The Commission Internationale de $\mathrm{l}^{\prime}$ Eclairage (CIE) color coordinates (see Table 2) of the compounds were determined from the respective electroluminescence spectra. The CIE color coordinates of compounds $\mathbf{1 a}, \mathbf{1} \mathbf{b}$, and $\mathbf{1 c}$ are $(0.4898,0.5021)$, $(0.4809,0.5095)$, and $(0.4820,0.5091)$. For the family 2 , the CIE color coordinates are $(0.4715,0.5166)$ for $2 \mathrm{a},(0.4718$, $0.5122)$ for $2 \mathbf{b}$, and $(0.4568,0.5293)$ for $2 \mathbf{c}$. All CIE coordinates correspond to orange emission.

The EL spectra of LEECs $\mathbf{1 a}, \mathbf{1} \mathbf{b}$, and $\mathbf{1 c}$ exhibit a single band with maxima emission wavelength of 575,573 , and $574 \mathrm{~nm}$, respectively. A single band is also observed for LEECs $2 \mathrm{a}-\mathrm{c}$ where the maximum emission wavelengths are $572 \mathrm{~nm}(2 \mathrm{a})$, $574 \mathrm{~nm}$ (2b), and 568 (2c). Hence, all six complexes exhibit similar maximum EL peak, which is red-shifted with respect to the PL emission peak, except for complex $\mathbf{1 b}$ and $\mathbf{1 c}$, which are slighty blue-shifted. Incorporation of the mesityl group does not significantly impact the color in the device, which is a behavior distinct to that observed in the neat film PL where mesityl substitution promotes a significant blue-shifting in the neat film (Figure 4). The emission spectra of one dominant band observed in electroluminescence is due to the efficient sequential trapping of electrons on holes and the emitting sites that are lowest in energy.

\section{CONCLUSIONS}

In summary, we have reported the preparation, the crystal structures, and the photophysical properties in neat thin film of two families of iridium(III) complexes of the form of $\left[\operatorname{Ir}\left(\mathrm{C}^{\wedge} \mathrm{N}\right)_{2}(\mathrm{dtBubpy})\right] \mathrm{PF}_{6}$ in both their racemic and $\Lambda$-, $\Delta$ enantiopure configurations. For both families of complexes, mirrored crystal unit cells and similar solid-state photophysical properties exist between the $\Lambda$ and $\Delta$ enantiomers. However, the photophysical properties of the enantiomers are different compared to the racemic analogues. LEEC devices have been fabricated using the $\Lambda$ and $\Delta$ enantiomers as well as the racemic analogues of both families, and reflecting the different photophysical properties in the solid state, different device performance have been achieved. Depending on the particular iridium complex family evaluated, we see positive and negative effects when employing enantiopure complexes in LEECs. We attribute the change in device behavior to differences in solid- 
state film morphology due to different packing of the two complex families. This study reveals the importance and the complexity that enantiopurity plays on the performance of LEEC devices.

\section{ASSOCIATED CONTENT}

\section{(S Supporting Information}

The Supporting Information is available free of charge on the ACS Publications website at DOI: 10.1021/acsami.6b14050. The research data supporting this publication can be accessed at http://dx.doi.org/10.17630/085105be-3161-4ff5-8511e26b56f533a0

Experimental section, characterization of precursors, ligands and iridium complexes, crystal structure of $\Lambda, \Lambda-D 1, \Delta . \Delta-\mathrm{D} 2$ and 1a, geometrical parameters of 1a, 1b, 1c, 2a, 2b, and 2c, supplementary optoelectronic data, and supplementary LEEC fabrication and characterization data; CCDC: 1490702-1490708 (PDF) $\mathrm{X}$-ray data (CIF)

\section{AUTHOR INFORMATION}

\section{Corresponding Author}

*E-mail: eli.zysman-colman@st-andrews.ac.uk. Fax: +44-1334 463808. Tel: +44-1334 463826.

ORCID

Eli Zysman-Colman: 0000-0001-7183-6022

Notes

The authors declare no competing financial interest.

\section{ACKNOWLEDGMENTS}

E.Z.-C. acknowledges the University of St Andrews and EPSRC (EP/M02105X/1) for financial support. We thank Umicore AG for the gift of materials. We thank the EPSRC UK National Mass Spectrometry Facility at Swansea University for analytical services. The authors further acknowledge financial support from the Spanish Ministry of Economy and Competitiveness (MINECO) via the Unidad de Excelencia Maria de Maeztu MDM-2015-0538, MAT2014-55200-R, and PCIN-2015-255 and the Generalitat Valenciana (Prometeo/2016/135). C.M. thanks the MINECO for her pre-doctoral contract.

\section{REFERENCES}

(1) For recent reviews on LEECs see: Costa, R. D.; Ortí, E.; Bolink, H. J.; Monti, F.; Accorsi, G.; Armaroli, N. Luminescent Ionic Transition-Metal Complexes for Light-Emitting Electrochemical Cells. Angew. Chem., Int. Ed. 2012, 51, 8178-8211.

(2) Rudmann, H.; Shimada, S.; Rubner, M. F. Solid-State LightEmitting Devices Based on the Tris-Chelated Ruthenium(II) Complex. 4. High-Efficiency Light-Emitting Devices Based on Derivatives of the Tris $\left(2,2^{\prime}\right.$-bipyridyl) Ruthenium(II) Complex. J. Am. Chem. Soc. 2002, 124, 4918-4921.

(3) Slinker, J. D.; Gorodetsky, A. A.; Lowry, M. S.; Wang, J.; Parker, S. T.; Rohl, R.; Bernhard, S.; Malliaras, G. G. Efficient Yellow Electroluminescence From a Single Layer of a Cyclometalated Iridium Complex. J. Am. Chem. Soc. 2004, 126, 2763-2767.

(4) Hu, T.; He, L.; Duan, L.; Qiu, Y. Solid-State Light-Emitting Electrochemical Cells Based on Ionic Iridium(iii) Complexes. J. Mater. Chem. 2012, 22, 4206-4215.

(5) Meier, S. B.; Tordera, D.; Pertegás, A.; Roldán-Carmona, C.; Ortí, E.; Bolink, H. J. Light-Emitting Electrochemical Cells: Recent Progress and Future Prospects. Mater. Today 2014, 17, 217-223.
(6) Lowry, M. S.; Bernhard, S. Synthetically Tailored Excited States: Phosphorescent, Cyclometalated Iridium(III) Complexes and Their Applications. Chem. - Eur. J. 2006, 12, 7970-7977.

(7) Ladouceur, S.; Swanick, K. N.; Gallagher-Duval, S.; Ding, Z.; Zysman-Colman, E. Strongly Blue Luminescent Cationic Iridium(III) Complexes with an Electron-Rich Ancillary Ligand: Evaluation of Their Optoelectronic and Electrochemiluminescence Properties. Eur. J. Inorg. Chem. 2013, 2013, 5329-5343.

(8) You, Y.; Park, S. Y. Phosphorescent Iridium(iii) Complexes: Toward High Phosphorescence Quantum Efficiency Through Ligand Control. Dalton Trans. 2009, 1267-1472.

(9) Tamayo, A. B.; Garon, S.; Sajoto, T.; Djurovich, P. I.; Tsyba, I. M.; Bau, R.; Thompson, M. E. Cationic Bis-cyclometalated Iridium(III) Diimine Complexes and Their Use in Efficient Blue, Green, and Red Electroluminescent Devices. Inorg. Chem. 2005, 44, 8723-8732.

(10) Helms, M.; Lin, Z.; Gong, L.; Harms, K.; Meggers, E. Method for the Preparation of Nonracemic Bis-Cyclometalated Iridium(III) Complexes. Eur. J. Inorg. Chem. 2013, 2013, 4164-4172.

(11) Göbel, P.; Ritterbusch, F.; Helms, M.; Bischof, M.; Harms, K.; Jung, M.; Meggers, E. Probing Chiral Recognition of Enzyme Active Sites with Octahedral Iridium(III) Propeller Complexes. Eur. J. Inorg. Chem. 2015, 2015, 1654-1659.

(12) Mazzeo, G.; Fuse, M.; Longhi, G.; Rimoldi, I.; Cesarotti, E.; Crispini, A.; Abbate, S. Vibrational Circular Dichroism and Chiroptical Properties of Chiral Ir(iii) Luminescent Complexes. Dalton Trans 2016, 45, 992-999.

(13) Chen, X.; Okamoto, Y.; Yano, T.; Otsuki, J. Direct Enantiomeric Separations of Tris(2-phenylpyridine) Iridium (III) Complexes on Polysaccharide Derivative-Based Chiral Stationary Phases. J. Sep. Sci. 2007, 30, 713-716.

(14) Meggers, E. Chiral Auxiliaries as Emerging Tools for the Asymmetric Synthesis of Octahedral Metal Complexes. Chem. - Eur. J. 2010, 16, 752-758.

(15) Yang, L.; von Zelewsky, A.; Nguyen, H. P.; Muller, G.; Labat, G.; Stoeckli-Evans, H. Stereoselective Synthesis of Cyclometalated Iridium (III) Complexes: Characterization and Photophysical Properties. Inorg. Chim. Acta 2009, 362, 3853-3856.

(16) Schaffner-Hamann, C.; von Zelewsky, A.; Barbieri, A.; Barigelletti, F.; Muller, G.; Riehl, J. P.; Neels, A. Diastereoselective Formation of Chiral Tris-Cyclometalated Iridium (III) Complexes: Characterization and Photophysical Properties. J. Am. Chem. Soc. 2004, 126, 9339-9348.

(17) Auffrant, A.; Barbieri, A.; Barigelletti, F.; Lacour, J.; Mobian, P.; Collin, J.-P.; Sauvage, J.-P.; Ventura, B. Bimetallic Iridium(III) Complexes Consisting of $\operatorname{Ir}($ ppy)2 Units (ppy = 2-Phenylpyridine) and Two Laterally Connected NN Chelates as Bridge: Synthesis, Separation, and Photophysical Properties. Inorg. Chem. 2007, 46, 6911-6919.

(18) Oyler, K. D.; Coughlin, F. J.; Bernhard, S. Controlling the Helicity of 2,2'-Bipyridyl Ruthenium(II) and Zinc(II) Hemicage Complexes. J. Am. Chem. Soc. 2007, 129, 210-217.

(19) Hamann, C.; von Zelewsky, A.; Neels, A.; Stoeckli-Evans, H. Diastereoselective Synthesis of Coordination Compounds: a Chiral Tripodal Ligand Based on Bipyridine Units and its Ruthenium(ii) and Iron(ii) Complexes. Dalton Trans. 2004, 402-406.

(20) Howson, S. E.; Allan, L. E. N.; Chmel, N. P.; Clarkson, G. J.; Deeth, R. J.; Faulkner, A. D.; Simpson, D. H.; Scott, P. Origins of Stereoselectivity in Optically Pure PhenylethaniminopyridinetrisChelates $\mathrm{M}(\mathrm{NN}) 3 \mathrm{n}+(\mathrm{M}=\mathrm{Mn}, \mathrm{Fe}, \mathrm{Co}, \mathrm{Ni}$ and $\mathrm{Zn})$. Dalton Trans. 2011, 40, 10416-10433.

(21) Coughlin, F. J.; Westrol, M. S.; Oyler, K. D.; Byrne, N.; Kraml, C.; Zysman-Colman, E.; Lowry, M. S.; Bernhard, S. Synthesis, Separation, and Circularly Polarized Luminescence Studies of Enantiomers of Iridium(III) Luminophores. Inorg. Chem. 2008, 47, 2039-2048.

(22) Citti, C.; Battisti, U. M.; Ciccarella, G.; Maiorano, V.; Gigli, G.; Abbate, S.; Mazzeo, G.; Castiglioni, E.; Longhi, G.; Cannazza, G. Analytical and Preparative Enantioseparation and Main Chiroptical 
Properties of Iridium(III) Bis(4,6-difluorophenylpyridinato)picolinato. J. Chromatogr. A 2016, 1467, 335-346.

(23) Fletcher, N. C.; Junk, P. C.; Reitsma, D. A.; Keene, F. R. Chromatographic Separation of Stereoisomers of Ligand-Bridged Diruthenium Polypyridyl Species. J. Chem. Soc., Dalton Trans. 1998, $133-138$.

(24) Fletcher, N. C.; Martin, C.; Abraham, H. J. Enantiomeric Programming in Tripodal Transition Metal Scaffolds. New J. Chem. 2007, 31, 1407-1411.

(25) Chepelin, O.; Ujma, J.; Wu, X.; Slawin, A. M. Z.; Pitak, M. B.; Coles, S. J.; Michel, J.; Jones, A. C.; Barran, P. E.; Lusby, P. J. Luminescent, Enantiopure, Phenylatopyridine Iridium-Based Coordination Capsules. J. Am. Chem. Soc. 2012, 134, 19334-19337.

(26) Xu, C.; Guenet, A.; Kyritsakas, N.; Planeix, J.-M.; Hosseini, M. W. Molecular Tectonics: Design of Enantiopure Luminescent Heterometallic Ir(III)-Cd(II) Coordination Network. Inorg. Chem. 2015, 54, 10429-10439.

(27) Marchi, E.; Sinisi, R.; Bergamini, G.; Tragni, M.; Monari, M.; Bandini, M.; Ceroni, P. Easy Separation of $\Delta$ and $\Lambda$ Isomers of Highly Luminescent [IrIII]-Cyclometalated Complexes Based on Chiral Phenol-Oxazoline Ancillary Ligands. Chem. - Eur. J. 2012, 18, 87658773 .

(28) Helms, M.; Wang, C.; Orth, B.; Harms, K.; Meggers, E. Proline and $\alpha$-Methylproline as Chiral Auxiliaries for the Synthesis of Enantiopure Bis-Cyclometalated Iridium(III) Complexes. Eur. J. Inorg. Chem. 2016, 2016 (18), 2896-2901.

(29) Kozhevnikov, V. N.; Zheng, Y.; Clough, M.; Al-Attar, H. A.; Griffiths, G. C.; Abdullah, K.; Raisys, S.; Jankus, V.; Bryce, M. R.; Monkman, A. P. Cyclometalated Ir(III) Complexes for High-Efficiency Solution-Processable Blue PhOLEDs. Chem. Mater. 2013, 25, 23522358.

(30) Rota Martir, D.; Bansal, A. K.; Di Mascio, V.; Cordes, D. B.; Henwood, A. F.; Slawin, A. M. Z.; Kamer, P. C. J.; Martinez-Sarti, L.; Pertegas, A.; Bolink, H. J.; Samuel, I. D. W.; Zysman-Colman, E. Enhancing the Photoluminescence Quantum Yields of Blue-Emitting Cationic Iridium(iii) Complexes Bearing Bisphosphine Ligands. Inorg. Chem. Front. 2016, 3, 218-235.

(31) Henwood, A. F.; Bansal, A. K.; Cordes, D. B.; Slawin, A. M. Z.; Samuel, I. D. W.; Zysman-Colman, E. Solubilised Bright Blue-Emitting Iridium Complexes for Solution Processed OLEDs. J. Mater. Chem. C 2016, 4, 3726-3737.

(32) Rota Martir, D.; Hedley, G. J.; Cordes, D. B.; Slawin, A. M. Z.; Escudero, D.; Jacquemin, D.; Kosikova, T.; Philp, D.; Dawson, D. M.; Ashbrook, S. E.; Samuel, I.; Zysman-Colman, E. Exploring the SelfAssembly and Energy Transfer of Dynamic Supramolecular IridiumPorphyrin Systems. Dalton Trans. 2016, 45, 17195-17205.

(33) Ladouceur, S.; Fortin, D.; Zysman-Colman, E. The Role of Substitution on the Photophysical Properties of 5,5'-diaryl-2,2'bipyridine (bpy*) in $[\operatorname{Ir}($ ppy)2(bpy*)]PF6 Complexes: A Combined Experimental and Theoretical Study. Inorg. Chem. 2010, 49, 56255641.

(34) Tordera, D.; Delgado, M.; Ortí, E.; Bolink, H. J.; Frey, J.; Nazeeruddin, M. K.; Baranoff, E. Stable Green Electroluminescence from an Iridium Tris-Heteroleptic Ionic Complex. Chem. Mater. 2012, 24, 1896-1903.

(35) Melhuish, W. H. Quantum Efficiences Of Fluorescence Of Organic Substances: Effect Of Solvent And Concentration Of The Fluorescent Solute 1. J. Phys. Chem. 1961, 65, 229-235.

(36) Parker, S. T.; Slinker, J. D.; Lowry, M. S.; Cox, M. P.; Bernhard, S.; Malliaras, G. G. Improved Turn-on Times of Iridium Electroluminescent Devices by Use of Ionic Liquids. Chem. Mater. 2005, 17, 3187-3190.

(37) Zysman-Colman, E.; Slinker, J. D.; Parker, J. B.; Malliaras, G. G.; Bernhard, S. Improved Turn-On Times of Light-Emitting Electrochemical Cells. Chem. Mater. 2008, 20, 388-396.

(38) AlTal, F.; Gao, J. Long-Term Testing of Polymer Light-Emitting Electrochemical Cells: Reversible Doping and Black Spots. Org. Electron. 2015, 18, 1-7.
(39) Schneider, G. E.; Pertegás, A.; Constable, E. C.; Housecroft, C. E.; Hostettler, N.; Morris, C. D.; Zampese, J. A.; Bolink, H. J.; Junquera-Hernández, J. M.; Ortí, E.; Sessolo, M. Bright and Stable Light-Emitting Electrochemical Cells Based on an Intramolecularly $\pi$ Stacked, 2-Naphthyl-Substituted Iridium Complex. J. Mater. Chem. C 2014, 2, 7047-7055

(40) Tordera, D.; Pertegás, A.; Shavaleev, N. M.; Scopelliti, R.; Ortí, E.; Bolink, H. J.; Baranoff, E.; Grätzel, M.; Nazeeruddin, M. K. Efficient Orange Light-Emitting Electrochemical Cells. J. Mater. Chem. 2012, 22, 19264-19268.

(41) Bünzli, A. M.; Constable, E. C.; Housecroft, C. E.; Prescimone, A.; Zampese, J. A.; Longo, G.; Gil-Escrig, L.; Pertegás, A.; Ortí, E.; Bolink, H. J. Exceptionally Long-Lived Light-Emitting Electrochemical Cells: Multiple Intra-Cation $\pi$-Stacking Interactions in $\left[\operatorname{Ir}\left(\mathrm{C}^{\wedge} \mathrm{N}\right) 2\right.$ $\left.\left(\mathrm{N}^{\wedge} \mathrm{N}\right)\right][\mathrm{PF} 6]$ Emitters. Chem. Sci. 2015, 6, 2843-2852. 